\title{
The stable isotopic signature of biologically produced molecular hydrogen $\left(\mathrm{H}_{2}\right)$
}

\author{
S. Walter ${ }^{1}$, S. Laukenmann ${ }^{2}$, A. J. M. Stams ${ }^{3}$, M. K. Vollmer ${ }^{4}$, G. Gleixner ${ }^{5}$, and T. Röckmann ${ }^{1}$ \\ ${ }^{1}$ Institute for Marine and Atmospheric research Utrecht (IMAU), Utrecht University, Utrecht, The Netherlands \\ ${ }^{2}$ Department of Atmospheric Chemistry, MPI for Chemistry, Mainz, Germany \\ ${ }^{3}$ Laboratory of Microbiology, Wageningen University, Wageningen, The Netherlands \\ ${ }^{4}$ Empa, Swiss Federal Laboratories for Materials Science and Technology, Laboratory for Air Pollution and Environmental \\ Technology, Dubendorf, Switzerland \\ ${ }^{5}$ Department of Biogeochemical Processes, Max Planck Institute for Biogeochemistry, Jena, Germany
}

Correspondence to: S. Walter (s.walter@uu.nl)

Received: 23 November 2011 - Published in Biogeosciences Discuss.: 22 December 2011

Revised: 16 May 2012 - Accepted: 29 September 2012 - Published: 24 October 2012

\begin{abstract}
Biologically produced molecular hydrogen $\left(\mathrm{H}_{2}\right)$ is characterised by a very strong depletion in deuterium. Although the biological source to the atmosphere is small compared to photochemical or combustion sources, it makes an important contribution to the global isotope budget of $\mathrm{H}_{2}$. Large uncertainties exist in the quantification of the individual production and degradation processes that contribute to the atmospheric budget, and isotope measurements are a tool to distinguish the contributions from the different sources. Measurements of $\delta D$ from the various $\mathrm{H}_{2}$ sources are scarce and for biologically produced $\mathrm{H}_{2}$ only very few measurements exist.

Here the first systematic study of the isotopic composition of biologically produced $\mathrm{H}_{2}$ is presented. In a first set of experiments, we investigated $\delta D$ of $\mathrm{H}_{2}$ produced in a biogas plant, covering different treatments of biogas production. In a second set of experiments, we investigated pure cultures of several $\mathrm{H}_{2}$ producing microorganisms such as bacteria or green algae. A Keeling plot analysis provides a robust overall source signature of $\delta D=-712 \%$ o $( \pm 13 \%$ o $)$ for the samples from the biogas reactor (at $38^{\circ} \mathrm{C}, \delta D_{\mathrm{H}_{2} \mathrm{O}}=+73.4 \%$ ),

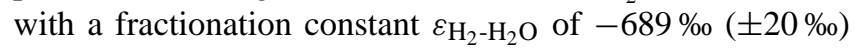
between $\mathrm{H}_{2}$ and the water. The five experiments using pure culture samples from different microorganisms give a mean source signature of $\delta D=-728 \%$ ( $( \pm 28 \%$ o , and a fraction-

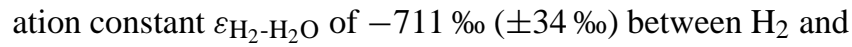
the water. The results confirm the massive deuterium depletion of biologically produced $\mathrm{H}_{2}$ as was predicted by the cal-
\end{abstract}

culation of the thermodynamic fractionation factors for hydrogen exchange between $\mathrm{H}_{2}$ and water vapour. Systematic errors in the isotope scale are difficult to assess in the absence of international standards for $\delta D$ of $\mathrm{H}_{2}$.

As expected for a thermodynamic equilibrium, the fractionation factor is temperature dependent, but largely independent of the substrates used and the $\mathrm{H}_{2}$ production conditions. The equilibrium fractionation coefficient is positively correlated with temperature and we measured a rate of change of $2.3 \% \circ /{ }^{\circ} \mathrm{C}$ between $45^{\circ} \mathrm{C}$ and $60^{\circ} \mathrm{C}$, which is in general agreement with the theoretical prediction of $1.4 \% \circ /{ }^{\circ} \mathrm{C}$.

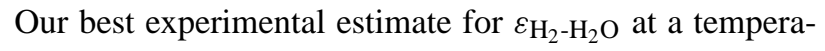
ture of $20^{\circ} \mathrm{C}$ is $-731 \%$ o $( \pm 20 \%$ ) for biologically produced $\mathrm{H}_{2}$. This value is close to the predicted value of $-722 \%$, and we suggest using these values in future global $\mathrm{H}_{2}$ isotope budget calculations and models with adjusting to regional temperatures for calculating $\delta D$ values.

\section{Introduction}

Molecular hydrogen $\left(\mathrm{H}_{2}\right)$ is the second most abundant reduced compound in the atmosphere, after methane $\left(\mathrm{CH}_{4}\right)$. With a global average mixing ratio of $\sim 530 \mathrm{ppb}$ (partsper-billion, nmole/mole) and an atmospheric lifetime of $\sim 2 \mathrm{yr}$, it is responsible for a large fraction of the chemical turnover of hydrogen atoms in the atmosphere and 
contributes significantly to atmospheric chemistry (Novelli et al., 1999; Hauglustaine and Ehhalt, 2002; Rahn et al., 2003 Ehhalt and Rohrer, 2009). By reaction with the hydroxyl radical $(\cdot \mathrm{OH})$, hydrogen indirectly increases the atmospheric lifetimes of other trace gases that also react with $\cdot \mathrm{OH}$, for example, $\mathrm{CH}_{4}$ and carbon monoxide (CO) (Prather, 2003; Schultz et al., 2003; Jacobson et al., 2005; Jacobson, 2008) and, therefore, acts as an 'indirect' greenhouse gas. In the stratosphere, oxidation of $\mathrm{H}_{2}$ is a source of water vapour, which is important for the radiative properties of the stratosphere and also forms the substrate for polar stratospheric clouds, which are key ingredients in the formation of the polar ozone holes (Tromp et al., 2003; Warwick et al., 2004; Feck et al., 2008; Jacobson, 2008).

$\mathrm{H}_{2}$ is considered as a promising future energy carrier. It can be produced chemically, physically and biologically. The shortage, increase in cost and climate impact of fossil fuels leads to increased interest in sustainable and clean production of $\mathrm{H}_{2}$. One possible source to accommodate the expected energy demand might be biologically produced $\mathrm{H}_{2}$, e.g., via fermentation or photosynthesis.

Numerous studies in the past have addressed the global atmospheric budget of $\mathrm{H}_{2}$, but still none of the individual source or sink strengths is constrained to better than $\pm 25 \%$ (Ehhalt and Rohrer, 2009). Additional information is expected to come from the analysis of the $\mathrm{H}_{2}$ isotopic composition $(\delta D)$, because the different sources of $\mathrm{H}_{2}$ have a very different deuterium content. $\delta D$ is defined as the relative deviation of the $\mathrm{D} / \mathrm{H}$ ratio in a sample from the same ratio in the international reference material Vienna Standard Mean Ocean Water (VSMOW). Also the kinetic fractionation in the two main removal processes, soil deposition and reaction with $\mathrm{OH}$, is different.

Tropospheric $\mathrm{H}_{2}$ is enriched in deuterium with $\delta D$ $\sim+130 \%$, (Gerst and Quay, 2001; Rhee et al., 2006; Rice et al., 2010; Batenburg et al., 2011) compared to surface emissions from fossil fuel combustion and biomass burning ( $\delta D$ approximately $-200 \%$ and $-300 \%$, respectively) (Gerst and Quay, 2001; Rahn et al., 2002; Röckmann et al., 2010a; Vollmer et al., 2010). As originally proposed by Gerst and Quay (2001) from budget closure, the photochemical sources of $\mathrm{H}_{2}$ are also enriched in deuterium with $\delta D$ between $\sim+100 \%$ and $+200 \%$ o, (Rahn et al., 2003; Röckmann et al., 2003, 2010b; Feilberg et al., 2007; Nilsson et al., 2007, 2010; Pieterse et al., 2009). Biologically produced $\mathrm{H}_{2}$ has the most exceptional isotopic composition. Biochemical reactions take place in the aqueous phase and, therefore, the isotopic composition of biologically produced $\mathrm{H}_{2}$ should reflect the thermodynamic isotope equilibrium between $\mathrm{H}_{2}$ and $\mathrm{H}_{2} \mathrm{O}$. Bottinga (1969) calculated fractionation factors for isotope equilibrium in the system $\mathrm{H}_{2}$ - water vapour. He predicts $\varepsilon_{\mathrm{H}_{2}-\mathrm{H}_{2} \mathrm{O}}$ values for biologically produced $\mathrm{H}_{2}$ of $-737 \%$ o to $-693 \%$, relative to the water, in the main biological relevant temperature range between $10^{\circ} \mathrm{C}$ and $40^{\circ} \mathrm{C}$. Up to now only few individual measurements have been carried out to experimentally determine the isotopic composition of biologically produced $\mathrm{H}_{2}$ and confirm the extremely depleted values calculated by Bottinga (1969). Rahn et al. (2002) measured headspace samples from a jar of termites with a value of $\delta D=-778 \%$ at a mixing ratio of $1.8 \mathrm{ppm}$ (parts-permillion, $\mu$ mole $/ \mathrm{mole}$ ), and $\delta D=-690 \%$ at a mixing ratio of $4 \mathrm{ppm}$ from a water headspace sample taken from an eutrophic pond. For none of these values the isotopic composition of the water was reported and it appears that the equilibrium isotope effect between $\mathrm{H}_{2}$ and $\mathrm{H}_{2} \mathrm{O}$ has never been experimentally verified. Today recent global modelling studies have incorporated biological sources with an isotopic composition of $\delta D=-628 \%$ (Price et al. 2007; Pieterse et al. 2011).

Although biologically produced $\mathrm{H}_{2}$ is only responsible for approximately $10 \%$ of the annual global $\mathrm{H}_{2}$ source (Novelli et al., 1999; Hauglustaine and Ehhalt, 2002; Ehhalt and Rohrer, 2009; Pieterse et al., 2011) the extreme deuterium depletion relative to ambient atmospheric $\mathrm{H}_{2}$ makes it a quite important contributor to the isotope budget (Price et al. 2007; Pieterse et al. 2011). An increasing demand and anthropogenic biological production of $\mathrm{H}_{2}$ by e.g., industrial fermentation of biogenic waste material is associated with an expected release to the atmosphere because of leakage during production, storage, transport and use. This may increase the contribution of highly deuterium-depleted $\mathrm{H}_{2}$ to the atmosphere.

Here we present the first systematic experimental evaluation of the isotope source signature of biologically produced $\mathrm{H}_{2}$, which is then compared to the theoretical calculations of Bottinga (1969). We measured the isotopic composition of fermentative produced molecular $\mathrm{H}_{2}$ in biogas, using different production conditions and substrates. Additionally we investigated $\mathrm{H}_{2}$ produced from pure cultures of fermentative bacteria (Caldicellulosiruptur saccharolyticus, Escherichia coli, and Clostridium acetobutylicum) and of one $\mathrm{N}_{2}$-fixer (Azospirillum brasiliensis). We also measured photosynthetically produced $\mathrm{H}_{2}$ from the common green algae Chlamydomonas reinhardtii.

\section{Experimental}

\subsection{Samples}

\subsubsection{Samples from a biogas plant}

Samples were provided from a biogas plant in Freising, Germany, where also the experiments were conducted. Experiments were carried out with batch cultures ( 21 Merck glass bottles) and continuous cultures (301 glass container). Both were fed with different substrates from surrounding agricultures such as corn, sunflower, cellulose, grass, wheat or mixtures of these substrates. For both treatments the same inoculum was used. It was provided from a pilot-plant scaled plant 
(35001 volume). An overview about used substrates and different treatments is given in Table 1.

The batch cultures consist of $1600 \mathrm{ml}$ inoculum and were fed once with $50 \mathrm{~g}$ substrate (organic dry substance, oDS) and incubated at a stable temperature of $38^{\circ} \mathrm{C}$. After 35 days, headspace gas samples were taken with gas tight syringes into evacuated $12 \mathrm{ml}$ glass tubes with an overpressure of approximately 1 bar.

The continuous cultures consist of 301 inoculum and were fed daily in the morning and incubated at temperatures of $38^{\circ} \mathrm{C}$ to $60^{\circ} \mathrm{C}$ depending on the treatment. The treatments also differ in the amount of substrate between 2 and $3.5 \mathrm{~kg}$ organic dry substance/day (oDS/d). Approximately $4 \mathrm{~h}$ after feeding, samples were taken at a syringe port at the fermenter with gas tight syringes into evacuated $12 \mathrm{ml}$ glass tubes with an overpressure of approximately 1 bar.

In total, three samples from batch cultures and 13 samples from continuous cultures were measured (see Table 1). Some samples were measured in duplicate or more. The headspace of pure inoculum was also sampled and measured.

\subsubsection{Pure culture experiments}

Headspace samples were taken from 5 pure cultures of known $\mathrm{H}_{2}$ producing organisms: (i) three common fermentative bacteria: Caldicellulosiruptur saccharolyticus, Escherichia coli and Clostridium acetobutylicum; (ii) one $\mathrm{N}_{2}$ fixing bacterium (Azospirillum brasiliensis, strain SP7); and (iii) one limnic green algae Chlamydomonas reinhardtii (SAG strain number 11-32b).

E. coli and $C$. saccharolyticus were grown with 10 or $20 \mathrm{mM}$ glucose and $0.2 \mathrm{gl}^{-1}$ yeast extract in the medium as described in Stams et al. (1993). These bacteria were grown in 120 -ml vials with $50 \mathrm{ml}$ medium or $250-\mathrm{ml}$ bottles with $100 \mathrm{ml}$ medium, and a gasphase of $\mathrm{N}_{2} / \mathrm{CO}_{2}(80 / 20)$. E. coli was grown at $37^{\circ} \mathrm{C}$ and $C$. saccharolyticus at $70^{\circ} \mathrm{C}$. C. acetobutylicum was grown at $37^{\circ} \mathrm{C}$ as described by Nimcevic et al. (1998). The gas phase was $\mathrm{N}_{2}$. Gas samples were taken from the cultures at the end of growth by gastight syringes and injected in sterile vacuum vials, previously flushed with pure nitrogen.

$12 \mathrm{ml}$ of preincubated A. brasiliensis (strain SP7) was used to inoculate $600 \mathrm{ml}$ of ampicillin medium in a closed 21 borosilicate bottle. Three replicates and one control were incubated for 5 days at $30^{\circ} \mathrm{C}$. The headspace gas volume was sampled into a pre-evacuated 11 glass container (NORMAG, Illmenau, Germany) sealed with two polychlorotrifluoroethylen (PCTFE) valves.

The green algae $C$. reinhardtii was cultivated in a sulfatelimited Tris-Acetate-Phosphate (TAP) medium as part of an experiment conducted in Switzerland and described in more detail by Haus et al. (2009). For the batch used in our isotope study, a $\mathrm{N}_{2}$ headspace technique in a glass bottle was applied. After approximately 8 days of incubation, several $\mathrm{ml}$ of headspace gas were extracted using a gastight syringe and injected into a pre-evacuated 11 glass container of the same type as mentioned above. Synthetic air, further purified from traces of $\mathrm{H}_{2}$ using a catalyst (Sofnocat 514, Molecular Products, Thaxted, UK) was added (to 1.9 bar total pressure) to dilute the sample and, thereby, making it suitable for $\mathrm{H}_{2}$ measurements. Initial $\mathrm{H}_{2}$ mixing ratio measurements were conducted at Empa before transferring the sample to IMAU for detailed $\mathrm{H}_{2}$ and $\delta D$ analysis. Results for $\mathrm{H}_{2}$ mixing ratios of Empa and IMAU are in agreement within the error bars and the direct comparison is not shown here.

\subsection{Determination of $\mathrm{H}_{2}$ mixing ratio and isotopic composition}

The mixing ratio and isotopic composition of molecular $\mathrm{H}_{2}$ was determined by using the experimental setup developed by Rhee et al. (2004) and modified as described in Röckmann et al. (2010b). Due to a lack of international isotope standards for $\mathrm{H}_{2}$, calibration is a critical issue. Our calibration scale has been described in Batenburg et al. (2011). Samples were measured randomly and within 35 days after collection. The measurements consist of the following steps: (1) The sample is cryogenically separated at $-240^{\circ} \mathrm{C}$, which means that all gaseous compounds, with the exception of $\mathrm{H}_{2}$ and some noble gases, are condensed; (2) The non-condensed fraction of the sample (including $\mathrm{H}_{2}$ ) is preconcentrated using a $5 \AA$ molecular sieve at $-210^{\circ} \mathrm{C}$; (3) $\mathrm{H}_{2}$ is focused on a capillary gas chromatographic column ( $5 \AA$ molecular sieve) and chromatographically purified from remaining contaminants at $50^{\circ} \mathrm{C}$; (4) the $\mathrm{D} / \mathrm{H}$ ratio of molecular $\mathrm{H}_{2}$ is determined by continuous flow isotope ratio mass spectrometry using a ThermoFinnigan Delta Plus XL instrument.

The analytical system is designed for measurement of air samples with $\mathrm{H}_{2}$ mixing ratios in the range of typical atmospheric air samples (e.g., Röckmann et al. 2003, 2010b; Rhee et al. 2006; Batenburg et al. 2011). The samples obtained from the biogas reactor and the individual cultures have extremely high $\mathrm{H}_{2}$ molar mixing ratios between $10 \mathrm{ppm}$ and $1.4 \%$ (see Table 1), which are outside the measurement range of our instrument. To a certain degree, the analytical system has some flexibility as regards high $\mathrm{H}_{2}$ mixing ratios because simply smaller samples can be inserted into the sample volume; however, in this study the values were that high that the samples had to be diluted. Two dilution methods were adapted for samples of pure cultures and biogas samples.

Several samples from the pure cultures were expanded into 21 electropolished stainless steel canisters that are routinely used in our laboratory for airborne air sampling (Kaiser et al., 2006; Laube et al., 2008, 2010 and referenced herein). They were diluted by a factor of approximately 2000 with $\mathrm{H}_{2}$-free synthetic $\mathrm{N}_{2}-\mathrm{O}_{2}$ mixtures. The mixtures were then measured as normal air samples. This procedure induces errors from the dilution itself (for the mixing ratios) and from unquantifiable blank levels of $\mathrm{H}_{2}$ in the dilution gas. Another disadvantage is that no reference gases are available in the 
Table 1. Molecular hydrogen $\left(\mathrm{H}_{2}\right)$ mixing ratio and $\delta D$ (vs. VSMOW) from different biogas production treatments and pure cultures. Columns 4 and 5 give the raw (i.e. measured) values for mixing ratio and $\delta D$, which are used in the Keeling plot in Fig. 1. Columns 6 and 7 give the final values of the pure sample after correction for the dilution with standard gas (with known $\mathrm{H}_{2}$ mixing ratio of 546.2 ppb, $\delta D+71.4 \%$, used for biogas samples) and $\mathrm{H}_{2}$ free gas (used for pure microorganism culture samples), respectively. Substrate was added in units of $\mathrm{kg}$ organic dry material per day [o DM/d]. Some samples are measured in duplicate or more. Uncertainties in the table are given for the reproducibility of the measurements or calculations as the average of absolute deviation of data from their mean. For single measurements we assume a mean uncertainty of $4.1 \%$ for mixing ratios and $2.4 \%$ for $\delta D$ values.

\begin{tabular}{|c|c|c|c|c|c|c|}
\hline Culture & $\begin{array}{l}\text { Temp. } \\
\left({ }^{\circ} \mathrm{C}\right)\end{array}$ & $\begin{array}{l}\text { Substrate } \\
\text { (organic dry material/day) }\end{array}$ & $\begin{array}{l}\text { Measured mixing ratio } \\
(\mathrm{ppb})\end{array}$ & $\begin{array}{l}\text { Measured } \delta D \\
(\%)\end{array}$ & $\begin{array}{l}\text { Corrected mixing ratio } \\
(\mathrm{ppm})\end{array}$ & $\begin{array}{l}\text { Corrected } \delta D \\
(\%)\end{array}$ \\
\hline inoculum & 38 & inoculum & 624 & -12 & 27 & -587 \\
\hline \multirow{2}{*}{$\begin{array}{l}\text { batch } \\
\text { culture }\end{array}$} & 38 & corn + sunflower & 575 & +35 & 10 & -636 \\
\hline & 38 & cellulose & 592 & +21 & 16 & -555 \\
\hline \multirow{9}{*}{$\begin{array}{l}\text { continuous } \\
\text { culture }\end{array}$} & 38 & grass, $2 \mathrm{~kg}$ o DM/d & 702 & -104 & 53 & -712 \\
\hline & 38 & corn, $2 \mathrm{~kg}$ o DM/d & 675 & -85 & 44 & -741 \\
\hline & 38 & corn, $2.5 \mathrm{~kg}$ o DM/d & 587 & +16 & 14 & -710 \\
\hline & 38 & corn, $3.5 \mathrm{~kg}$ o $\mathrm{DM} / \mathrm{d}$ & 689 & -90 & 49 & -699 \\
\hline & 38 & grass, $2 \mathrm{~kg}$ o DM/d $(n=2)$ & $1170 \pm 23$ & $-350 \pm 6$ & $212 \pm 5$ & $-718 \pm 21$ \\
\hline & 38 & grass, $2 \mathrm{~kg}$ o DM/d $(n=3)$ & $2262 \pm 135$ & $-520 \pm 9$ & $587 \pm 38$ & $-708 \pm 20$ \\
\hline & 38 & grass, $2 \mathrm{~kg}$ o $\mathrm{DM} / \mathrm{d}$ & 1133 & -327 & 201 & -696 \\
\hline & 60 & $\begin{array}{l}30 \% \text { grass }+30 \% \text { corn }+40 \% \text { cereals } \\
(n=2)\end{array}$ & $2510 \pm 66$ & $-535 \pm 7$ & $671 \pm 26$ & $-703 \pm 20$ \\
\hline & & Microorganism species & & & & \\
\hline \multirow{5}{*}{$\begin{array}{l}\text { Pure } \\
\text { microorganism } \\
\text { culture }\end{array}$} & 70 & Caldicellulosiruptur saccharolyticus & 6360 & -758 & 13887 & -758 \\
\hline & 37 & Escherichia coli $(n=2)$ & $3507 \pm 9$ & $-758 \pm 0$ & $8179 \pm 21$ & $-758 \pm 0$ \\
\hline & 37 & Clostridium acetobutylicum & 11422 & -741 & 13403 & -741 \\
\hline & 20 & Chlamydomonas reinhardtii & 596 & -721 & 2285 & -721 \\
\hline & 30 & Azospirillum brasiliensis $(n=5)$ & $4043 \pm 1096$ & $-556 \pm 24$ & $1339 \pm 420$ & $-664 \pm 19$ \\
\hline
\end{tabular}

region of the extremely deuterium-depleted samples, and the isotope scale has to be extrapolated very far outside the range that was used for calibrating the reference gas $(-9.5 \%$ to $+205 \%$ ) (Batenburg et al., 2011). Therefore, for the samples from the biogas plant and the $\mathrm{N}_{2}$ fixer (A. brasiliensis), a standard addition method was developed. Small amounts of a sample (usually approximately $1 \mathrm{ml}$ ) were added manually with a gas tight syringe to air from the laboratory reference air cylinder $\left(\mathrm{H}_{2}\right.$ mixing ratio $=546.2 \mathrm{ppb}, \delta D=+71.4 \%$ o (Batenburg et al., 2011). For the biogas samples following this procedure the measured mixing ratios after dilution were between $575 \mathrm{ppb}$ and $2510 \mathrm{ppb}$, and $\delta D$ values were between $+35 \%$ and $-535 \%$ (Table 1 ). This means that in the measurement procedure itself a "Keeling plot analysis" is involved, because the $\mathrm{H}_{2}$ and $\mathrm{HD}$ measured in the isotope ratio mass spectrometer is then a mixture of the well-known reference air and the unknown sample (Fig. 1 for the biogas samples). The isotopic composition of the original sample is then inferred by extrapolation of the linear fit to the correlation between $\delta D$ and inverse mixing ratio to 0 (y-axis intercept). On the one hand, this introduces an error from the extrapolation, but on the other hand the measured $\delta D$ values are much closer to the range that was used for calibration of the reference gas. The manual injection of the reference gas with a syringe leads to a relatively high error for the reproducibility of mixing ratios for the original biogas samples $( \pm 4.1 \%)$, whereas the reproducibility for $\delta D$ is not much worse than for normal atmospheric air samples $( \pm 2.4 \%)$, since an error in mixing ratio only changes the location of the mixture on the mixing line, but not the y-axis intercept (see Fig. 1). The error for measurement reproducibility is given as the average of absolute deviation of data from their mean.

The isotopic composition of the water used in the incubation experiments was determined by Hydroisotop $\mathrm{GmbH}$, Schweitenkirchen, Germany. 
The $\delta D$ is defined as followed:

$\delta D=\frac{[D / H]_{\text {sample }}}{[D / H]_{\text {standard }}}-1$

Fractionation constants $\varepsilon_{\mathrm{H}_{2}-\mathrm{H}_{2} \mathrm{O}}$ of $\mathrm{H}_{2}$ relative to $\mathrm{H}_{2} \mathrm{O}$ were calculated as

$$
\begin{aligned}
\varepsilon_{\mathrm{H}_{2}-\mathrm{H}_{2} \mathrm{O}} & =\alpha_{\mathrm{H}_{2}-\mathrm{H}_{2} \mathrm{O}}-1=\frac{[D / H]_{\mathrm{H}_{2}}}{[D / H]_{\mathrm{H}_{2} \mathrm{O}}}-1 \\
& =\frac{\delta D_{\mathrm{H}_{2}}+1}{\delta D_{\mathrm{H}_{2} \mathrm{O}}+1}-1=\frac{\delta D_{\mathrm{H}_{2}}-\delta D_{\mathrm{H}_{2} \mathrm{O}}}{\delta D_{\mathrm{H}_{2} \mathrm{O}}+1}
\end{aligned}
$$

where $\alpha$ is the fractionation factor between the $\mathrm{H}_{2}$ product and the $\mathrm{H}_{2} \mathrm{O}$ reactant. All $\delta D$ values are reported relative to Vienna Standard Mean Ocean Water (VSMOW). $\mathrm{H}_{2}$ mixing ratios are reported as molar mixing ratios in parts per million $(\mathrm{ppm}=\mu \mathrm{mole} / \mathrm{mole})$ or parts per billion $(\mathrm{ppb}=\mathrm{nmole} / \mathrm{mole})$, or in percent $(\%)$ for high mixing ratios.

\section{Results and discussion}

Table 1 provides a summary of the results. The $\mathrm{H}_{2}$ content of the samples differed considerably. While the samples of the batch incubations from the biogas reactor contained relatively low $\mathrm{H}_{2}$ mixing ratios with a maximum of $16 \mathrm{ppm}$ $(0.0016 \%)$, the continuous incubations showed values up to 671 ppm $(0.0671 \%)$. In such biogas reactors, hydrogen produced by anaerobic bacteria is metabolised by the activity of methanogenic archaea, resulting in rather low hydrogen partial pressures (Stams and Plugge, 2009). The highest $\mathrm{H}_{2}$ mixing ratios up to $13887 \mathrm{ppm}$ or $1.4 \%$ were measured in the headspace of the pure culture of $C$. saccharolyticus.

A Keeling plot analysis provides a powerful tool to establish a robust overall source signature for the samples from the biogas reactor. The results of all measurements can fit very well $\left(R^{2}=0.999\right)$ on a straight line with a y-axis intercept (source signature) of $\delta D=-713 \%$ ( $( \pm 13 \%$ ). It should be noted that this fit is not equally constrained by all samples, but more influenced by samples with high mixing ratios. To examine the effect of a possible nonlinearity in the isotope scale the analysis was repeated using only samples with $\delta D$ values $>-100 \%$. This results in a source signature of $-718 \%$, which shows that nonlinearity of the isotope scale does not significantly affect our results.

Results for the individual samples are also included in Table 1 . The samples from the batch incubations show individually a large degree of variability, but this is due to the low $\mathrm{H}_{2}$ mixing ratios of the sample-reference gas mixtures measured (see Sect. 2). For individual samples, the Keeling plot analysis covers only a small range in inverse mixing ratio and the associated errors after extrapolation to 0 are large. The average of all individual source signature determinations is

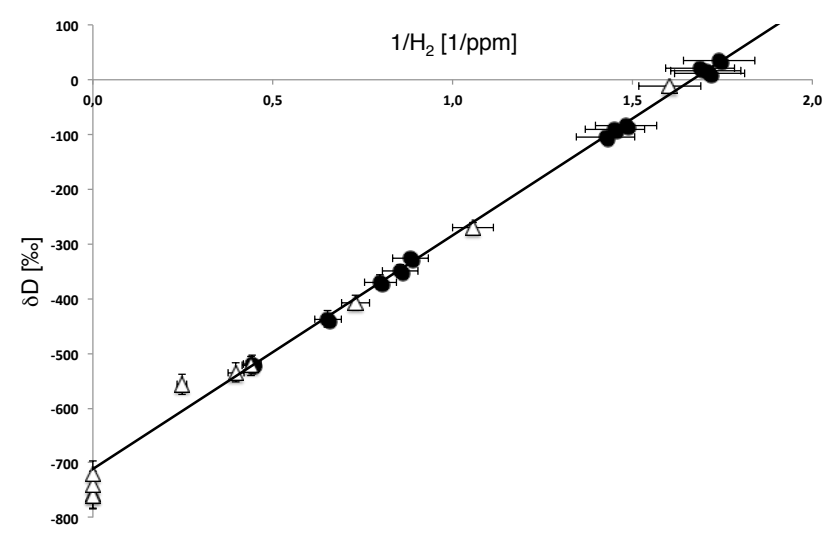

Fig. 1. Keeling plot of the diluted samples from the biogas reactor at $38^{\circ} \mathrm{C}$ (black dots, excluding the inoculum). The least-square fit result is $y=427.4 x-711.55, R^{2}=0.999$. For completeness the results of the treatments at different temperatures, of the inoculum and the pure cultures are also included in the figure (triangles), but not taken into account for determination of the source signature.

$\delta D=-706 \% \circ( \pm 37 \%, n=22)$. This is in very good agreement with the Keeling plot approach above, which provides the more robust constraint, because the influence of the samples with low mixing ratios is reduced in the Keeling plot approach.

The $\delta D$ source signatures of the pure cultures range between $-664 \%$ ofor $A$. brasiliensis to $-758 \%$ for $E$. coli and C. saccharolyticus and give a mean source signature of $\delta D=$ $-728 \%$ ( $( \pm 28 \%$ ) (Table 2$)$. Overall, the results from the different experimental setups confirm the very depleted source signature of biological $\mathrm{H}_{2}$, but there are differences between the different experimental setups. For further interpretation, the $\delta D$ values of the $\mathrm{H}_{2}$ produced must be compared to the source water (Table 2). The isotopic composition of the waters used in the biogas plant in Freising was $\delta D=-73.4 \%$ o $( \pm 1.5 \%$ ). For the cultivation of the microorganisms the isotopic composition of the used water was $-65.6 \%$ o $( \pm 1.5 \%$ o (C. rheinhardtii, Switzerland) and $-52.1 \%$ ( $\pm 1.5 \%$ ) (fermenters cultivated in Wageningen). The isotopic composition of the water used in the cultivation of A. brasiliensis in Munich was not determined, but is assumed to be close to typical tap water in Freising $(\delta D=-73.4 \%$ ). With this information, the fractionation constant $\varepsilon$ between $\mathrm{H}_{2}$ and $\mathrm{H}_{2} \mathrm{O}$ can be calculated Eq. (2), which eliminates the water as free parameter. It is evident from the results in Table 2 that the variability between the different experimental setups remains when corrected for the different waters.

The fact that the $\mathrm{H}_{2}$ samples from the pure cultures were measured after dilution, and the biogas samples with the online mixing approach is unlikely to cause the difference, as a potential contamination during dilution of the pure culture samples should not lead to even lower $\delta D$ values for the mixtures. It was beyond the scope of this project to further 
Table 2. Isotopic source signature of produced $\mathrm{H}_{2}\left(\delta D_{\mathrm{H}_{2}}\right)$, isotopic composition of the water used in the incubation $\left(\delta D_{\mathrm{H}_{2} \mathrm{O}}\right)$, and isotopic

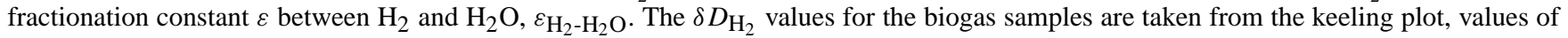
$\varepsilon$ from Bottinga (1969) are interpolated to the actual temperature. All values are in \%o.

\begin{tabular}{|c|c|c|c|c|}
\hline Sample origin & $\delta D_{\mathrm{H}_{2}}$ & $\delta D_{\mathrm{H}_{2} \mathrm{O}}$ & $\varepsilon_{\mathrm{H}_{2}-\mathrm{H}_{2} \mathrm{O}}$ & Bottinga (1969) $\varepsilon_{\mathrm{H}_{2}-\mathrm{H}_{2} \mathrm{O}}$ \\
\hline Biogas (Keeling plot), $38^{\circ} \mathrm{C}-60^{\circ} \mathrm{C}(n=24)$ & $-713 \pm 13$ & $-73.4 \pm 1.5$ & $-691 \pm 20$ & \\
\hline Biogas (Keeling plot), $38^{\circ} \mathrm{C}(n=15)$ & $-712 \pm 13$ & $-73.4 \pm 1.5$ & $-689 \pm 20$ & $-695 \%$ \\
\hline Azospirillum brasiliensis, $30^{\circ} \mathrm{C}(n=5)$ & $-664 \pm 19$ & $-73.4 \pm 1.5$ & $-637 \pm 19$ & $-707 \%$ \\
\hline Caldicellulosiruptur saccharolyticus, $70^{\circ} \mathrm{C}$ & -758 & $-52.1 \pm 1.5$ & -745 & $-650 \%$ \\
\hline Escherichia coli, $37^{\circ} \mathrm{C}$ & $-758 \pm 0$ & $-52.1 \pm 1.5$ & $-745 \pm 3$ & $-697 \%$ \\
\hline Clostridium acetobutylicum, $37^{\circ} \mathrm{C}(n=2)$ & -741 & $-52.1 \pm 1.5$ & -726 & $-697 \%$ \\
\hline Chlamydomonas reinhardtii, $20^{\circ} \mathrm{C}$ & -721 & $-65.5 \pm 1.5$ & -701 & $-722 \%$ \\
\hline \multicolumn{5}{|l|}{$\begin{array}{l}\text { Sample biogas (grass/corn/cereals) at incubation } \\
\text { temperatures of }\end{array}$} \\
\hline $45^{\circ} \mathrm{C}(n=2)$ & $-734 \pm 22$ & $-73.4 \pm 1.5$ & $-713 \pm 24$ & -685 \\
\hline $50^{\circ} \mathrm{C}(n=2)$ & $-726 \pm 21$ & $-73.4 \pm 1.5$ & $-704 \pm 24$ & -678 \\
\hline $55^{\circ} \mathrm{C}(n=2)$ & $-711 \pm 21$ & $-73.4 \pm 1.5$ & $-688 \pm 23$ & -671 \\
\hline $60^{\circ} \mathrm{C}(n=2)$ & $-703 \pm 20$ & $-73.4 \pm 1.5$ & $-680 \pm 21$ & -664 \\
\hline
\end{tabular}

investigate whether these differences are significant, but this would be an interesting task for the future. In the absence of further information, it may not be appropriate to simply average the results from this to some degree arbitrary selection of samples to obtain a representative mean.

The result from the biogas samples is best constrained, however, this value is determined for a temperature range of $38^{\circ} \mathrm{C}$ to $60^{\circ} \mathrm{C}$. Including only biogas samples at $38^{\circ} \mathrm{C}$ (inoculum and treatments at higher temperatures are excluded from the Keeling plot, Fig. 1) we end up with a $\delta D$ of $-712 \% \circ \pm 13 \%$ and a fractionation constant $\varepsilon_{\mathrm{H}_{2}-\mathrm{H}_{2} \mathrm{O}}$ of $-689 \%$ $\pm 20 \%$. This value is our best estimate for a frac-

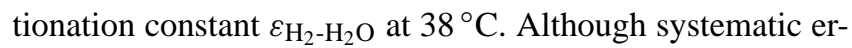
rors in the isotopic scale cannot be excluded due to a lack of international isotope standards, the good agreement with the theoretically calculated value of $\delta D=-695 \%$ (Bottinga, 1969) provides strong support for the validity of our results.

Bottinga (1969) also reports the temperature dependence of $\varepsilon_{\mathrm{H}_{2}-\mathrm{H}_{2} \mathrm{O}}$. We determined this temperature dependence experimentally over the incubation range $45^{\circ} \mathrm{C}-60^{\circ} \mathrm{C}$ with otherwise identical conditions (same inoculum and substrate, $30 \%$ grass, $30 \%$ maize, $40 \%$ cereals). As expected for an enzymatic-catalysed reaction in this temperature range, the mixing ratio of $\mathrm{H}_{2}$ is increasing with increasing temperatures (Fig. 2a). Figure $2 \mathrm{~b}$ shows that $\varepsilon_{\mathrm{H}_{2}-\mathrm{H}_{2} \mathrm{O}}$ increases with increasing incubation temperature from $-713 \%$ at $45^{\circ} \mathrm{C}$ to $-680 \%$ at $60^{\circ} \mathrm{C}$, thus, by $2.3 \% \circ /{ }^{\circ} \mathrm{C}$. Gray diamonds in Fig. $2 \mathrm{~b}$ indicate the theoretically predicted temperature dependency from Bottinga (1969), which is slightly smaller with $1.4 \% \circ /{ }^{\circ} \mathrm{C}$ over the same temperature range. The measurements show a distinct offset of $28 \%$ at $45^{\circ} \mathrm{C}$ reducing to $16 \%$ at $60{ }^{\circ} \mathrm{C}$, relative to the theoretical results over this temperature range (Fig. 2). This offset is slightly larger than our estimated experimental uncertainty and remains at present unexplained. Possible contributing factors in the measurements are the potential errors in the absolute isotope calibration (Batenburg et al. 2011) or a nonlinearity in the isotope scale at very low $\delta D$ values, which is not obvious from the Keeling plot. Nevertheless, the overall temperature dependence is in good qualitative agreement with the calculations of Bottinga (1969), and we conclude that the experimental techniques are sufficiently advanced now to detect such small changes in the region of very depleted isotope values.

In order to derive a revised $\delta D$ value for $\mathrm{H}_{2}$ from biological sources that can be used in global models or isotope budget calculations, we calculated $\varepsilon_{\mathrm{H} 2-\mathrm{H} 2 \mathrm{O}}$ at a mean temperature of $20^{\circ} \mathrm{C}$ using the measured value at $38^{\circ} \mathrm{C}$ and our experimentally determined temperature dependence, yielding a value of $\varepsilon_{\mathrm{H}_{2}-\mathrm{H}_{2} \mathrm{O}}=-731 \%$ o $( \pm 20 \%$ o). For calculating a global average $\delta D$ value of $\mathrm{H}_{2}$ from biological sources we used a global average value of $\delta D$ of precipitation of $\delta D=-37.8 \%$ (Hoffmann et al. 1998; Bowen and Revenaugh, 2003), and then calculate $\delta D=-741 \%$ $( \pm 20 \%$ ). Using the theoretical temperature dependence of Bottinga, we calculate $\varepsilon_{\mathrm{H}_{2}-\mathrm{H}_{2} \mathrm{O}}=-715 \%$ ( $\pm 20 \%$ ) and $\delta D=-726 \%$ o $( \pm 20 \%$ o). Our experimental values are in a very good agreement to the predicted value by Bottinga (1969) of $\varepsilon_{\mathrm{H}_{2}-\mathrm{H}_{2} \mathrm{O}}=-722 \%$, which gives a $\delta D=$ $-733 \%$ ( $20^{\circ} \mathrm{C}, \delta D$ of precipitation of $-37.8 \%$ o).

\section{Summary, conclusions and outlook}

The isotopic composition of biologically produced $\mathrm{H}_{2}$ was investigated systematically and our measurements confirm the massive deuterium depletion as predicted by Bottinga (1969). Using a Keeling plot analysis, we establish an overall source signature of $\delta D=-712 \%$ o $( \pm 13 \%$ ) for biologically produced $\mathrm{H}_{2}$, with a fractionation constant of 


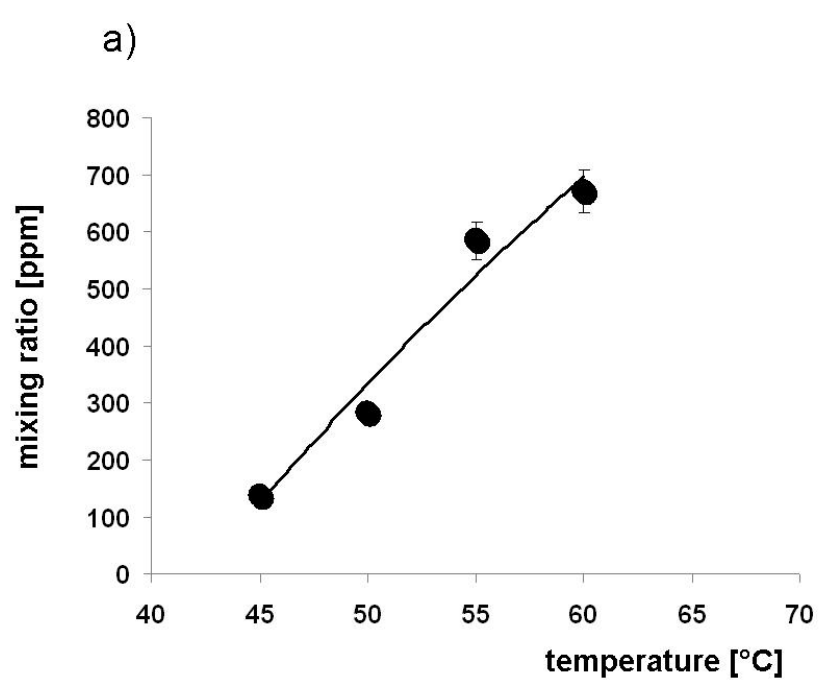

b)

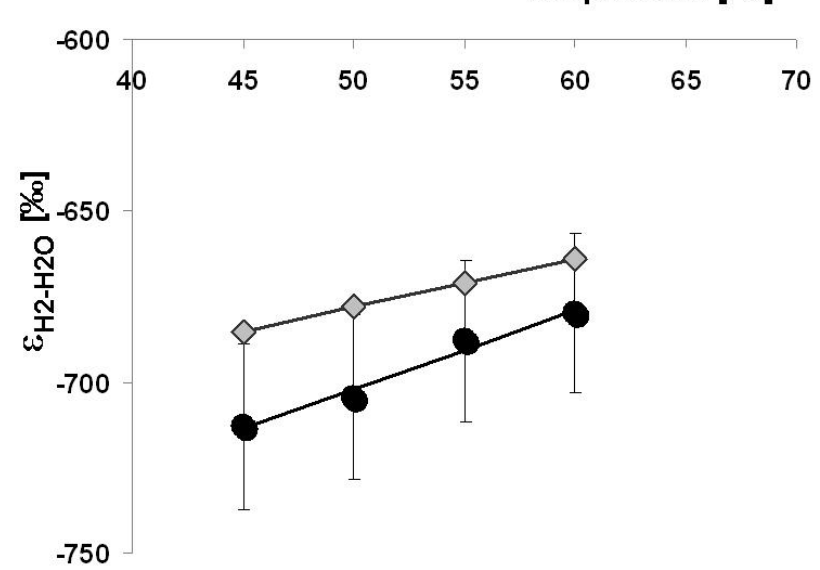

Fig. 2. Dependency of $\mathrm{H}_{2}$ mixing ratio (a) and $\varepsilon_{\mathrm{H}_{2}-\mathrm{H}_{2} \mathrm{O}}$ (b) on incubation temperature for continuous incubations from the biogas plant under otherwise identical conditions (substrate $30 \%$ grass, $30 \%$ maize, $40 \%$ cereals). Gray diamonds in figure (b) indicate the theoretically predicted value from Bottinga (1969). Results of the measured fit lines are: (a) $y=1990 \ln (x)-7453 ; R^{2}=0.96$; (b) $y=2.3 x-817.4 ; R^{2}=0.98$. Note: With respect to enzymatic catalised production of hydrogen, a logarithmic fit is chosen for the relation between temperature and mixing ratio. Note: the error bars given are not representing the reproducibility of the duplicate measurements, but also take into account the general uncertainties by using mean relative errors of $2.9 \%$ for $\delta D$ and $5.4 \%$ for the mixing ratio.

$\varepsilon_{\mathrm{H}_{2}-\mathrm{H}_{2} \mathrm{O}}-689 \%$ $\pm 20 \%$ o between the $\mathrm{H}_{2}$ and the source water at $38^{\circ} \mathrm{C}$ and a $\delta D_{\mathrm{H}_{2} \mathrm{O}}$ of $-73.4 \%$ o. The temperature de-

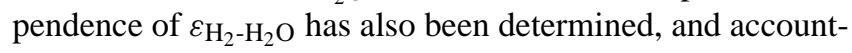
ing for the temperature effect the fractionation constant is extrapolated to $\varepsilon_{\mathrm{H}_{2}-\mathrm{H}_{2} \mathrm{O}}=-731 \%$ ( $( \pm 20 \%$ o $)$ at $20^{\circ} \mathrm{C}$. This gives an experimentally received source signature of approximately $\delta D=-741 \%$ o $( \pm 20 \%$ o ) for biologically produced $\mathrm{H}_{2}$ at mean temperatures $\left(20^{\circ} \mathrm{C}\right)$ and mean $\delta D$ of precip- itation $(-37.8 \%$ ). Thus, we suggest using these values in global models, rather than the value of $-628 \%$ o that has been assumed in recent global model studies (Price et al., 2007; Pieterse et al., 2011).

As expected for a thermodynamic equilibrium, the isotopic fractionation is independent of used substrates in the samples from the biogas plant. Samples from individual microorganism cultures confirm the depletion in general, but show even slightly lower $\delta D$ values; whereas $\mathrm{H}_{2}$ produced from a nitrogen fixing species had slightly higher $\delta D$ values. These differences could be caused by extremely high mixing ratios and dilution effects, but this needs further detailed investigation.

Due to its extreme deuterium depletion, biological $\mathrm{H}_{2}$, thus, has a high leverage in the global atmospheric $\mathrm{H}_{2}$ isotope budget. Biological $\mathrm{H}_{2}$ accounts for only $\sim 10 \%$ of the total $\mathrm{H}_{2}$ source, but this fraction is depleted by $\sim 772 \%$ relative to the ambient reservoir of $\sim+130 \%$ (note that $\delta$ values do not add linearly), so including this source or not makes a huge difference of $>70 \%$ in the atmospheric isotope budget.

The new results imply that the $\delta D$ values of biological $\mathrm{H}_{2}$ are distinctly lower than what was included in the two recent global model studies of $\delta D_{\mathrm{H}_{2}}$ (Price et al., 2007; Pieterse et al., 2011). First studies by Pieterse et al. (2011) included a sensitivity test for a change in the isotope source signature from $-628 \%$ o to $-700 \%$ and found that this would change the atmospheric isotope budget by $-4 \%$. The demand and production of biologically produced $\mathrm{H}_{2}$ is expected to increase in the future, and a small increase in the production and release to the atmosphere of e.g., $1 \mathrm{Tg} \mathrm{yr}^{-1}$ would lead to an observable decrease in $\delta D$ in atmospheric $\mathrm{H}_{2}$ and can influence the global isotope budgeting.

Despite the large advance in $\mathrm{H}_{2}$ measurement techniques, the isotopic signature of this gas is still challenging to measure. Intercomparison experiments within the European "EUROHYDROS" project reveal mean deviations of $<1 \%$ in $\mathrm{H}_{2}$ and provide confidence in the reproducibility of the mixing ratios (Yver et al., 2011), but a lack of international isotope standards could still cause systematic errors in the isotopic scale. This should be taken into account when interpreting isotopic data.

Acknowledgements. We thank Susanne Voerkelius of Hydroisotop $\mathrm{GmbH}$ for the isotope analysis of the water samples in this project. Peter Haus, Tobias Mühlethaler, and Carolin Verbree have conducted the Chlamydomonas reinhardtii cultivation experiment as part of the middle school thesis project. Also thanks to Anton Hartmann, Research Center Munich, Germany for preparation of the bacillus Azospirillum brasiliensis.

This project was supported by the NWO (Netherlands Organisation for Scientific Research), NWO project number 816.01.001.

Edited by: U. Seibt 


\section{References}

Batenburg, A. M., Walter, S., Pieterse, G., Levin, I., Schmidt, M., Jordan, A., Hammer, S., Yver, C., and Röckmann, T.: Temporal and spatial variability of the stable isotopic composition of atmospheric molecular hydrogen: observations at six EUROHYDROS stations, Atmos. Chem. Phys., 11, 6985-6999, doi:10.5194/acp11-6985-2011, 2011.

Bottinga, Y: Calculated fractionation factors for carbon and hydrogen isotope exchange in the system calcite-carbon dioxide-graphite-methane-hydrogen-water vapour, Geochim. Cosmochim. Ac., 33, 49-64, 1969.

Bowen, G. J. and J. Revenaugh: Interpolating the isotopic composition of modern meteoric precipitation, Water Resour. Res., 39, 1299, doi:10.1029/2003WR002086, 2003.

Ehhalt, D. H. and Rohrer, F.: The tropospheric cycle of $\mathrm{H}_{2}$ : a critical review, Tellus B, 61, 500-535, 2009.

Feck, T., Grooß, J. U., and Riese, M.: Sensitivity of Arctic ozone loss to stratospheric $\mathrm{H}_{2} \mathrm{O}$, Geophys. Res. Lett., 35, L01803, doi:10.1029/2007GL031334, 2008.

Feilberg, K. L., Johnson, M. S., Bacak, A., Röckmann, T., and Nielsen, C. J.: Relative tropospheric photolysis rates of HCHO and HCDO measured at the European photoreactor facility, J. Phys. Chem. A, 111, 9034-9046, 2007.

Gerst, S. and Quay, P.: Deuterium component of the global molecular hydrogen cycle, J. Geophys. Res., 106, 5021-5031, 2001.

Hauglustaine, D. A. and Ehhalt, D. H.: A three-dimensional model of molecular hydrogen in the troposphere, J. Geophys. Res., 107, 4330-4346, doi:10.1029/2001JD001156, 2002.

Haus, P., Mühlethaler, T., and Verbree, C.: Wasserstoffproduktion mit Grünalgen, Maturarbeit, Kantonsschule Aarau, Switzerland, 2009.

Hoffmann, G., Werner, M., and Heimann, M.: The water isotope module of the ECHAM atmospheric general circulation modelA study on time scales from days to several years, J. Geophys. Res., 103, 16871-16896, 1998.

Jacobson, M. Z.: Effects of wind-powered hydrogen fuel cell vehicles on stratospheric ozone and global climate, Geophys. Res. Lett., 35, L19803, doi:10.1029/2008GL035102, 2008.

Jacobson, M. Z., Colella, W. G., and Golden, D. M.: Cleaning the air and improving health with hydrogen fuel-cell vehicles, Science, 308, 1901-1905, 2005.

Kaiser, J., Engel, A., Borchers, R., and Röckmann, T.: Probing stratospheric transport and chemistry with new balloon and aircraft observations of the meridional and vertical N2O isotope distribution, Atmos. Chem. Phys., 6, 3535-3556, doi:10.5194/acp6-3535-2006, 2006.

Laube, J. C., Engel, A., Bönisch, H., Möbius, T., Worton, D. R., Sturges, W. T., Grunow, K., and Schmidt, U.: Contribution of very short-lived organic substances to stratospheric chlorine and bromine in the tropics - a case study, Atmos. Chem. Phys., 8, 7325-7334, doi:10.5194/acp-8-7325-2008, 2008.

Laube, J. C., Martinerie, P., Witrant, E., Blunier, T., Schwander, J., Brenninkmeijer, C. A. M., Schuck, T. J., Bolder, M., Röckmann, T., van der Veen, C., Bönisch, H., Engel, A., Mills, G. P., Newland, M. J., Oram, D. E., Reeves, C. E., and Sturges, W. T.: Accelerating growth of HFC-227ea (1,1,1,2,3,3,3-heptafluoropropane) in the atmosphere, Atmos. Chem. Phys., 10, 5903-5910, doi:10.5194/acp-10-5903-2010, 2010.
Nilsson, E. J. K., Johnson, M. S., Taketani, F., Matsumi, Y., Hurley, M. D., and Wallington, T. J.: Atmospheric deuterium fractionation: $\mathrm{HCHO}$ and $\mathrm{HCDO}$ yields in the $\mathrm{CH}_{2} \mathrm{DO}+\mathrm{O}_{2}$ reaction, Atmos. Chem. Phys., 7, 5873-5881, doi:10.5194/acp-7-5873-2007, 2007.

Nilsson, E. J. K., Andersen, V. F., Skov, H., and Johnson, M. S.: Pressure dependence of the deuterium isotope effect in the photolysis of formaldehyde by ultraviolet light, Atmos. Chem. Phys., 10, 3455-3462, doi:10.5194/acp-10-3455-2010, 2010.

Nimcevic, D., Schuster, M., and Gapes, J. R.: Solvent production by Clostridium beijerinckii NRRL B592 growing on different potato media, Appl. Microbiol. Biot., 50, 426-428, 1998.

Novelli, P. C., Lang, P. M., Masarie, K. A., Hurst, D. F., Myers, R., and Elkins, J. W.: Molecular hydrogen in the troposphere: Global distribution and budget, J. Geophys. Res., 104, 3042730444, 1999.

Pieterse, G., Krol, M. C., and Röckmann, T.: A consistent molecular hydrogen isotope chemistry scheme based on an independent bond approximation, Atmos. Chem. Phys., 9, 8503-8529, doi:10.5194/acp-9-8503-2009, 2009.

Pieterse, G., Krol, M. C., Batenburg, A. M., Steele, L. P., Krummel, P. B., Langenfelds, R. L., and Röckmann, T.: Global modelling of $\mathrm{H} 2$ mixing ratios and isotopic compositions with the TM5 model, Atmos. Chem. Phys., 11, 7001-7026, doi:10.5194/acp-11-70012011, 2011.

Prather, M. J.: An environmental experiment with $\mathrm{H}_{2}$ ?, Science, 302, 581-582, 2003.

Price, H., Jaegle, L., Rice, A., Quay, P., Novelli, P. C., and Gammon, R.: Global budget of molecular hydrogen and its deuterium content: Constraints from ground station, cruise, and aircraft observations, J. Geophys. Res., 112, D22108, doi:10.1029/2006JD008152, 2007.

Rahn, T., Kitchen, N., and Eiler, J. M.: D/H ratios of atmospheric $\mathrm{H}_{2}$ in urban air: Results using new methods for analysis of nanomolar $\mathrm{H}_{2}$ samples, Geochim. Cosmochim. Acta, 66, 2475-2481, 2002.

Rahn, T., Eiler, J. M., Boering, K. A., Wennberg, P. O., McCarthy, M. C., Tyler, S., Schauffler, S., Donnelly, S., and Atlas, E.: Extreme deuterium enrichment in stratospheric hydrogen and the global atmospheric budget of $\mathrm{H}_{2}$, Nature, 424, 918-921, 2003.

Rhee, T. S., Mak, J., Röckmann, T., and Brenninkmeijer, C. A. M.: Continuous-flow isotope analysis of the deuterium/hydrogen ratio in atmospheric hydrogen, Rapid Commun. Mass Sp., 18, 299306, 2004.

Rhee, T. S., Brenninkmeijer, C. A. M., and Röckmann, T.: The overwhelming role of soils in the global atmospheric hydrogen cycle, Atmos. Chem. Phys., 6, 1611-1625, doi:10.5194/acp-61611-2006, 2006.

Rice, A., Quay, P., Stutsman, J., Gammon, R., Price, H., and Jaegle, L.: Meridional distribution of molecular hydrogen and its deuterium content in the atmosphere, J. Geophys. Res., 115, D12306, doi:10.1029/2009JD012529, 2010.

Röckmann, T., Rhee, T. S., and Engel, A.: Heavy hydrogen in the stratosphere, Atmos. Chem. Phys., 3, 2015-2023, doi:10.5194/acp-3-2015-2003, 2003.

Röckmann, T., Gómez Álvarez, C. X., Walter, S., Veen, C. V., Wollny, A. G., Gunthe, S. S., Helas, G., Pöschl, U., Keppler, F., Greule, M., and Brand, W. A.: The isotopic composition of $\mathrm{H}_{2}$ from wood burning - dependency on combustion efficiency, 
moisture content and $\delta D$ of local precipitation, J. Geophys. Res., 115, D17308, doi:10.1029/2009JD013188, 2010a.

Röckmann, T., Walter, S., Bohn, B., Wegener, R., Spahn, H., Brauers, T., Tillmann, R., Schlosser, E., Koppmann, R., and Rohrer, F.: Isotope effect in the formation of $\mathrm{H}_{2}$ from $\mathrm{H}_{2} \mathrm{CO}$ studied at the atmospheric simulation chamber SAPHIR, Atmos. Chem. Phys., 10, 5343-5357, doi:10.5194/acp-10-53432010, 2010b.

Schultz, M. G., Diehl, T., Brasseur, G. P., and Zittel, W.: Air pollution and climate-forcing impacts of a global hydrogen economy, Science, 302, 624-627, 2003.

Stams, A. J. M., van Dijk, J. B., Dijkema, C., and Plugge, C. M.: Growth of syntrophic propionate-oxidizing bacteria with fumarate in the absence of methanogenic bacteria, Appl. Environ. Microbiol., 59, 1114-1119, 1993.

Stams, A. J. M. and Plugge, C. M.: Electron transfer in syntrophic communities of anaerobic bacteria and archaea, Nat. Rev. Microbiol., 7, 568-577, doi:10.1038/nrmicro2166, 2009.

Tromp, T. K., Shia, R.-L., Allen, M., Eiler, J. M., and Yung, Y. L.: Potential environmental impact of a hydrogen economy on the stratosphere, Science, 300, 1740-1742, 2003.
Vollmer, M. K., Walter, S., Bond, S. W., Soltic, P., and Röckmann, T.: Molecular hydrogen $\left(\mathrm{H}_{2}\right)$ emissions and their isotopic signatures (H/D) from a motor vehicle: implications on atmospheric $\mathrm{H}_{2}$, Atmos. Chem. Phys., 10, 5707-5718, doi:10.5194/acp-105707-2010, 2010.

Warwick, N. J., Bekki, S., Nisbet, E. G., and Pyle, J. A.: Impact of a hydrogen economy on the stratosphere and troposphere studied in a 2-D model, Geophys. Res. Lett., 31, L05107, doi:10.1029/2003GL019224, 2004.

Yver, C. E., Pison, I. C., Fortems-Cheiney, A., Schmidt, M., Chevallier, F., Ramonet, M., Jordan, A., Søvde, O. A., Engel, A., Fisher, R. E., Lowry, D., Nisbet, E. G., Levin, I., Hammer, S., Necki, J., Bartyzel, J., Reimann, S., Vollmer, M. K., Steinbacher, M., Aalto, T., Maione, M., Arduini, J., O’Doherty, S., Grant, A., Sturges, W. T., Forster, G. L., Lunder, C. R., Privalov, V., Paramonova, N., Werner, A., and Bousquet, P.: A new estimation of the recent tropospheric molecular hydrogen budget using atmospheric observations and variational inversion, Atmos. Chem. Phys., 11, 3375-3392, doi:10.5194/acp-11-3375-2011, 2011. 